\title{
Peripheral Primitive Neuro-Ectodermal Tumor - A Case Report
}

\author{
Arijit Sen ${ }^{1}$, Abhishek Basu ${ }^{2}$, Seheli Bandyopadhyay ${ }^{3}$, Arnab Bhattacharjee ${ }^{4}$ \\ I Department of Radiotherapy, Narayana Superspeciality Hospital, Howrah, India \\ 2 Department of Radiotherapy, R.G.Kar Medical College And Hospital, Kolkata, India \\ 3 Department of Radiotherapy, R.G.Kar Medical College And Hospital, Kolkata, India \\ ${ }_{4}$ Department of Radiotherapy, Tata Memorial Hospital, Mumbai, India
}

\begin{abstract}
Peripheral primitive neuroectodermal tumours (pPNETs) are uncommon tumours constituting $1 \%$ of all soft tissue sarcomas. Duodeno jejunal junction is an uncommon location of pPNET. The clinical, radiological, histopathological and immunohistochemical characteristics of this case are described here. Multimodality treatments of such tumours include surgery, chemotherapy and radiotherapy. We present here an extremely rare case of peripheral primitive neuro-ectodermal tumour of the duodeno - jejunal junction in a 38year-old male.
\end{abstract}

Keywords: Peripheral primitive neuro-ectodermal tumour, duodeno jejunal

\section{Introduction}

Peripheral primitive neuroectodermal tumours (pPNETs) are uncommon tumours constituting $1 \%$ of all soft tissue sarcomas [1]. They constitute a group of embryonic malignant tumours collectively designated as small round cell tumours. The tumours are derived from the neuroectoderm but have not developed and differentiated in the way a normal neuron would, and so the cells appear "primitive." They are often considered as part of the Ewing's sarcoma family of tumours, which exhibit neuroepithelial differentiation. The onset of the tumour is insidious and patients often have no specific clinical symptoms. [1,2] The diagnosis of a pPNET requires the combination of clinical symptoms, pathological characteristics, immunohistochemical features and cytogenetic analysis. This tumour can occur at any age, although the peak age incidence is during adolescence and young adulthood. [1,2] In general, PNETs often exhibits aggressive behaviour with a poor prognosis, 5-year disease-free survival rate being $45 \%-55 \%$. [2] The most common locations of peripheral PNETs are the thoracopulmonary region, followed by the retroperitoneal, paravertebral soft tissues, and the head and neck region. The incidence of peripheral PNET in the abdomen and pelvis, including the retroperitoneum, is about $14 \%$ of all peripheral PNETs. [2] Multimodality treatments of such tumours include surgery, chemotherapy and radiotherapy with major drug regimens being combinations of Inj. Vincristine, Doxorubicin, Cyclophosphamide, Ifosphamide, Etoposide and/or Dactinomycin (the so called VAC alternating with IE regime).

We present here an extremely rare case of peripheral primitive neuro-ectodermal tumour of the duodeno - jejunal junction in a 38-year-old male. The clinical history and radiological and histopathological findings are presented.

\section{History and Physical examination}

\section{Case Report}

A 38-year-old male patient was admitted to the Surgery department of our hospital in early April, 2014. The patient suffered from mild abdominal pain, nausea, vomiting, anorexia and weight loss since the preceding five months. The patient had no history of fever, jaundice, altered bowel habits or irregularities of the autonomic nervous system. On examination, the patient was afebrile, anicteric and slightly pale. An immobile firm, nontender mass about $8 \mathrm{~cm} \mathrm{X} 6 \mathrm{~cm}$ without clearly defined margins was identified in the left upper quadrant by palpation. No superficial lymph nodes were palpable clinically.

\section{Laboratory and Radiological Findings}

On Contrast Enhanced CT scan of the abdomen, a large lobulated inhomogeneously enhancing soft tissue mass of gut at the duodeno - jejunal (DJ) flexure $(6 \mathrm{~cm} \times 9 \mathrm{~cm} \times 10 \mathrm{~cm}$ in size $)$ was seen causing luminal narrowing of D-J junction with dilatation of proximal duodenum [Fig 1]. No mesenteric lymph nodes or retroperitoneal lymphadenopathy was present. No ascites was observed. CT scan of thorax and bone marrow biopsy were also normal.

\section{Diagnosis and Treatment}


The patient underwent surgical resection of the mass in February 2014. At laparotomy, a $15 \mathrm{~cm} \times 12$ $\mathrm{cm} \times 11 \mathrm{~cm}$ mass was found involving the $4^{\text {th }}$ part of duodenum and the adjacent D-J junction. The duodenum appeared to be hugely dilated. The mass was adhered to the other part of nearby small bowel and descending colon. Disseminated metastases were found in the whole of the omentum and small bowel mesentery. The liver appeared to be free. Resection anastomosis of the $4^{\text {th }}$ part of duodenum to the proximal jejunum along with a part of the descending colon was done in end to end fashion.

On gross examination a friable mass of size $13 \mathrm{~cm} \times 12 \mathrm{~cm} \times 12 \mathrm{~cm}$ alongwith a conglomerated mass of small intestine was seen. A lymph node in the mesentery was also noted. Histopathologically there were intermediate sized atypical lymphoid cells arranged in sheets in diffuse pattern expanding submucosa and serosa and infiltrating into mesentery [Fig 2]. Both proximal and distal margins were free. The microscopic picture was of small round cell tumour. Immunohistochemistry (IHC) showed malignant round cell tumour with expression of MIC 2 and Cytokeratin. The tumor was immunonegative for LCA, CD20, CD3, CD138, and c-kit, Desmin, SMA, S-100, Synaptophysin, Chromogranin A, CD 68, CD163, MPO, CD30, and Calretinin.

The patient then received chemotherapy with Inj. Vincristine $2 \mathrm{mg}$ IV Day 1 , Inj. Doxorubicin $75 \mathrm{mg} / \mathrm{m}^{2}$ IV Day 1, Inj. Cyclophosphamide $1200 \mathrm{mg} / \mathrm{m}^{2}$ IV Day1, 3 weekly alternating with Inj. Ifosphamide $1800 \mathrm{mg} / \mathrm{m}^{2}$ IV Day 1 to Day 5 with Inj. Etoposide $100 \mathrm{mg} / \mathrm{m}^{2}$ IV Day 1 - Day 5, for a total of 8 cycles. There was only mild haematological and gastrointestinal toxicity during chemotherapy which was managed conservatively.

A follow up CT scan after completion of 6 months of chemotherapy showed a large lobulated heterogeneously enhancing solid mass of size $11 \mathrm{~cm} \times 6 \mathrm{~cm} \times 7 \mathrm{~cm}$ in the left side of abdomen encasing segments of jejunal loops with luminal narrowing [Fig 3,4]. Plaques like peritoneal deposits were also noted at the right subdiaphragmatic, perihepatic space and pelvis. Multiple enlarged mesenteric lymph nodes were also noted. This CT scan suggested the progressive nature of the disease as per RECIST criteria version 1.1 [3]. Although options of salvage chemotherapy and palliative radiation were discussed with the patient, he denied any further oncological treatment and opted for best supportive care.

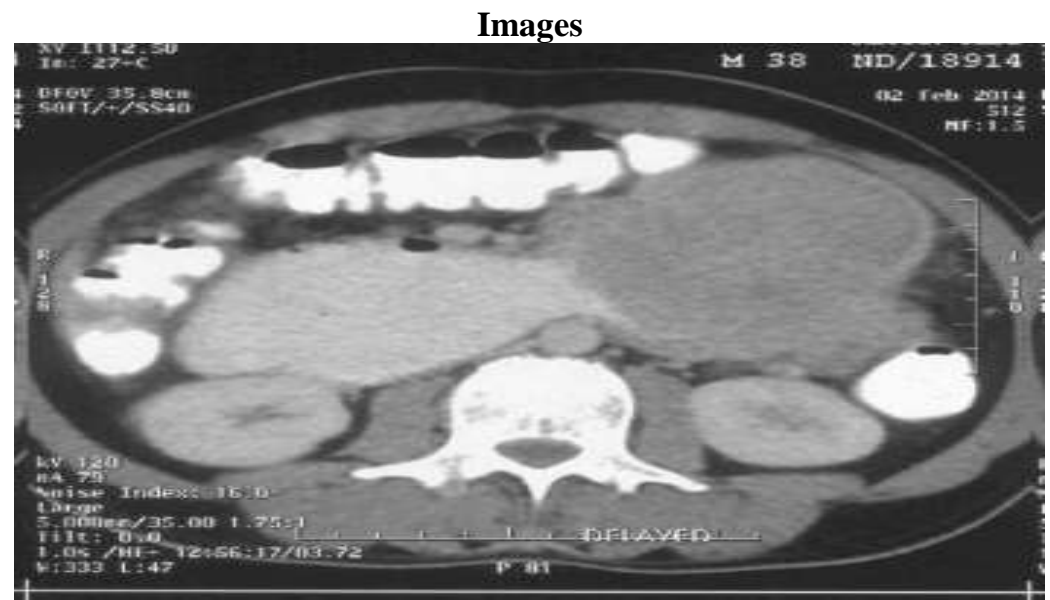

Fig 1: Pre- op CT Scan of abdomen showing a large lobulated heterogeneously enhancing soft tissue mass at left upper abdomen causing luminal narrowing of duodeno jejunal junction with dilatation of proximal duodenum

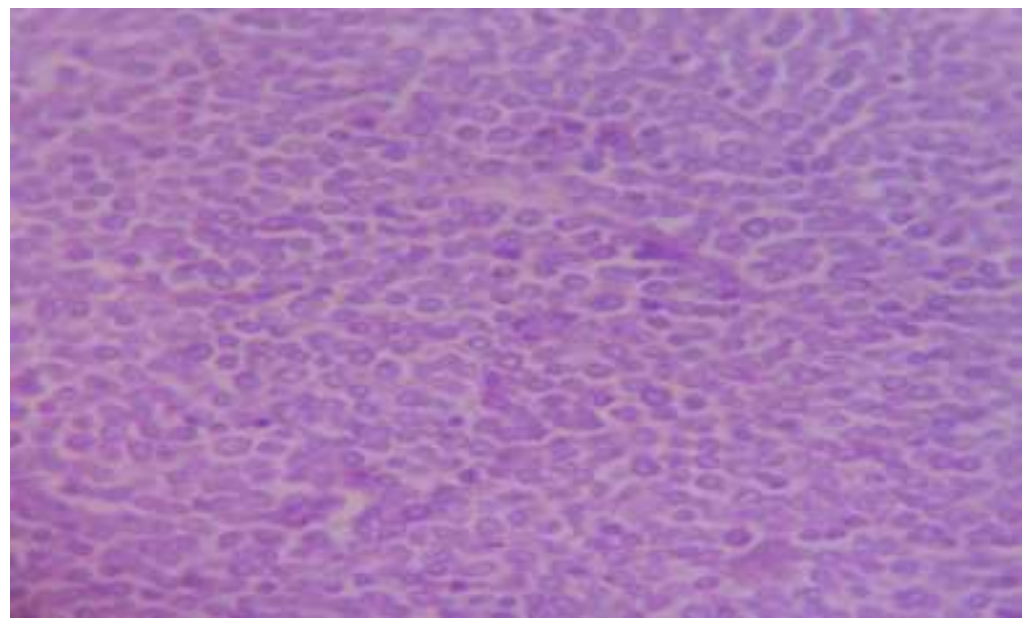


Fig 2: Histopathology shows small round cell tumour with hyperchromatic nuclei

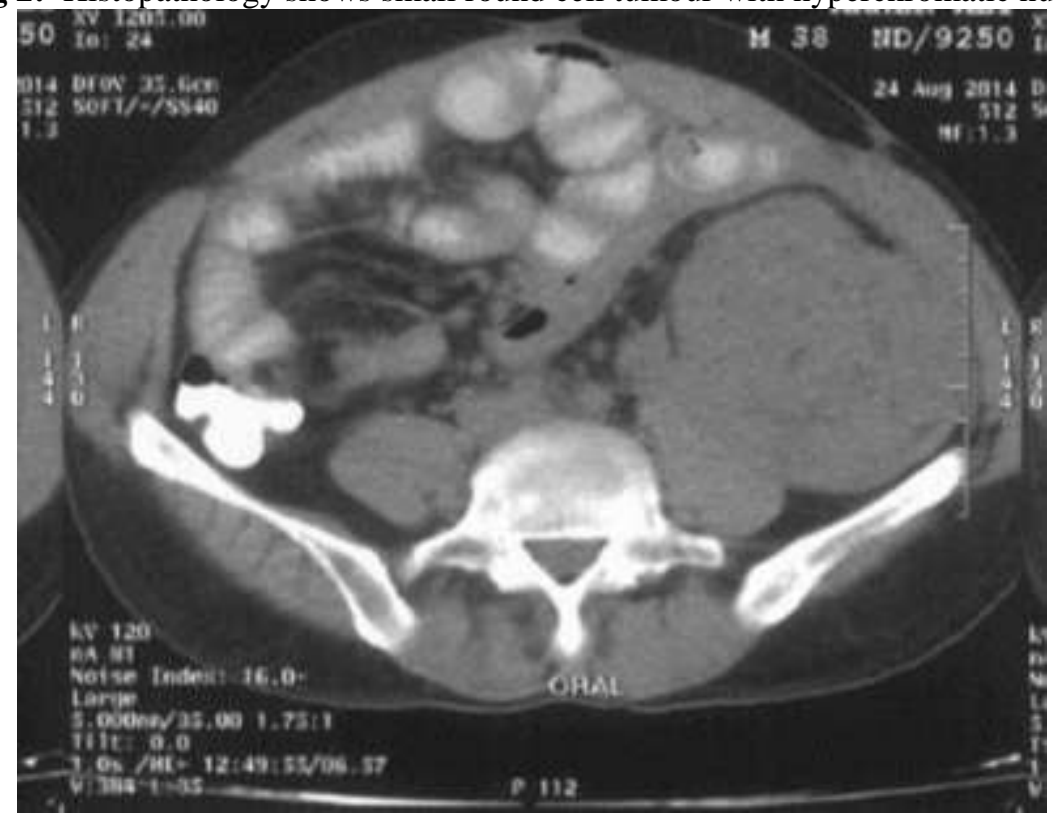

Fig 3: CT Scan whole abdomen 6 months after completion of chemotherapy showing large lobulated heterogeneously enhancing solid mass of size $11 \times 7 \times 6 \mathrm{~cm}$ in left side of abdomen encasing long segments of jejunal loops with luminal narrowing

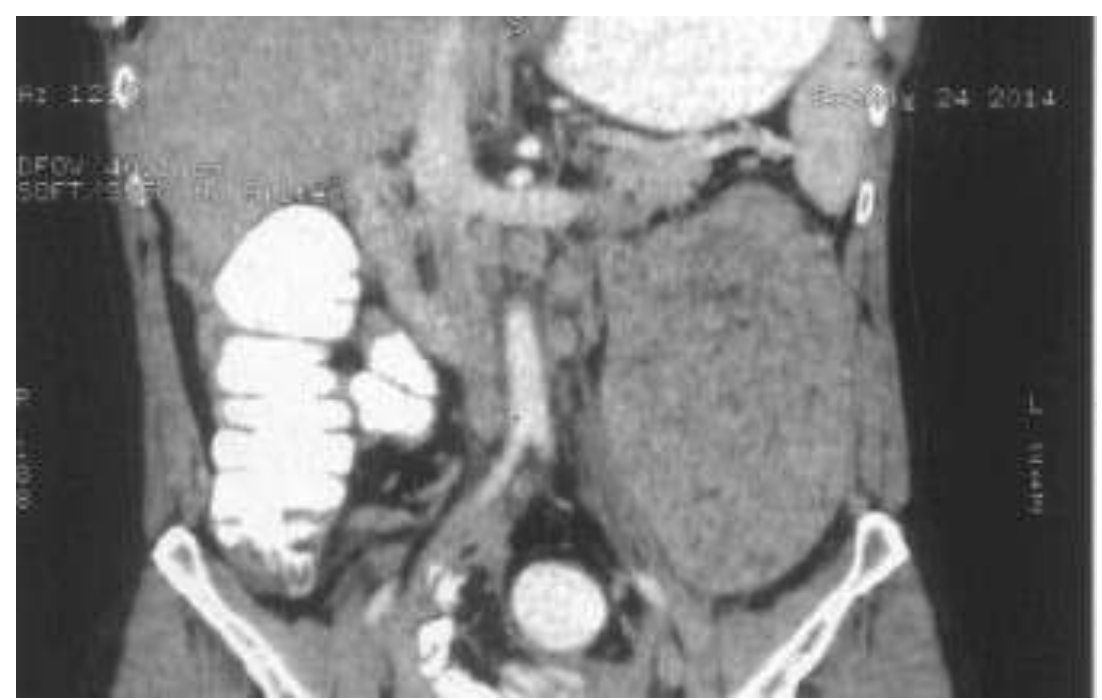

Fig 4: CT Scan - Sagittal section of whole abdomen showing lobulated heterogeneously enhancing mass in left side of abdomen with peritoneal deposits and multiple lymph nodes in mesenteric, retroperitoneal, bilateral left external and internal iliac denoting progressive disease

\section{Discussion}

The term 'Ewing sarcoma' (ES) has been used to denote tumours that lack neuroectodermal differentiation as assessed by light microscopy, immunohistochemistry and electron microscopy, whereas the term peripheral Primitive Neuroectodermal Tumours (pPNETs) are a group of small round cell tumours of neural crest origin that arise outside the central and sympathetic nervous system and exhibit neuroectodermal features. [4]. Originally thought to be a separate entity, PNET is now known to commonly share similar immunohistochemical characteristics and an identical chromosomal translocation t $(11 ; 22)(\mathrm{q} 24 ; \mathrm{q} 12)$ with ES. The two diseases are now treated as a single entity [4,5].

In general, PNETs are rare tumours, more prevalent in children. They may occur in the central nervous system such as non pineal supratentorial PNET, medulloblastoma and pinealoblastoma or may occur peripherally resembling soft tissue sarcomas. Although Ewing's sarcomas are more common in the bone there are examples of extra osseous tumours that may resemble PNET. 
There have been a number of case reports for peripheral PNETs including those in the eye [6,7], gynaecological organs $[8,9,10]$ and intraabdominal sites [11,12], kidneys [13,14], skin and subcutaneous tissue [15]. Among all these sites intraabdominal site is very rare. There are only five reported cases of gastric PNETs which were treated by surgery followed by chemotherapy $[16,17,18,19,20]$. The most important differential diagnosis is carcinoma (undifferentiated carcinoma or poorly differentiated neuroendocrine carcinoma). The other main differential diagnoses are considered to be lymphoma, melanoma, synovial sarcoma, rhabdomyosarcoma, and small round cell desmoplastic tumour.

PNETs are highly aggressive malignant tumours with almost inevitable local recurrence and distant metastasis. Metastasis to bone, bone marrow, lymph nodes, lung, liver and other organs have been reported. Currently, the accepted treatments of PNETs are surgical resection with adjuvant chemotherapy with or without radiotherapy. Chemotherapy protocols with Cyclophosphamide, Doxorubicin and Vincristine alternating with Ifphosphamide and Etoposide are adopted to promote therapeutic efficacy. Local radiation therapy is used with some therapeutic efficacy. Unfortunately, all of these treatments are relatively unsatisfactory [21].

\section{Conclusion}

In summary, we report a case of PNET arising in the duodeno jejunal junction (the first reported case to our knowledge). They are very rare and have high metastatic potential and often refractory to treatment. Immunohistochemistry is required for confirmation of the diagnosis. Multimodality treatment with surgery, chemotherapy and radiotherapy offers some benefit but the ultimate outcomes are often suboptimal.

\section{References}

[1]. Maccioni F, Della Rocca C, Salvi PF, Manicone AM, Ascarelli A, Longo F, et al. Malignant peripheral neuroectodermal tumor (MPNET) of the kidney. Abdom Imaging. 2000;25:103-6. [PubMed: 10652933]

[2]. Jurgens H, Bier V, Harms D, Beck J, Brandeis W, Etspuler W, et al. Malignant peripheral neuroectodermal tumors: A retrospective analysis of 42 patients. Cancer.1988;61:349-57. [PubMed: 3334970]

[3]. Therasse P, Arbuck SG, Eisenhauer EA, 7. et al: New guidelines to evaluate the response to treatment in solid tumors. European Organization for Research and Treatment of Cancer, National Cancer Institute of the United States, National Cancer Institute of Canada. J Natl Cancer Inst 92: 205-216, 2000

[4]. 4.Ushigome S, Machinami R and Sorensen PH: Ewing sarcoma/Primitive neuroectodermal tumour (PNET). In: World Health Organization Classification of Tumours. Pathology and Genetics of Tumours of Soft Tissue and Bone. Fletcher CDM, Unni KK and Mertens F (eds). IARC Press, Lyon, pp298-300, 2002.

[5]. Skubitz KM and D'Adamo DR: Sarcoma. Mayo Clin Proc 82: 9. 1409-1432, 2007.

[6]. Shuangshoti S, Menakanit W, Chanwaivit W, Suwanela : Primary intraorbital extraocular primitive neuroectodermal tumour. Br J Opthalmo 1986, 70:543-8.

[7]. Tamer C, Oksuz H, Hakverdi S, Karazincir S, Balci A, Yaldiz M: Primary peripheral primitive neuroectodermal tumour of the orbit. Can J Opthalmol 2007, 42:138-40.

[8]. Pauwels P, Ambrose P, Hattinger C, Lammens M, Dal Cin P, Ribot J, Struyk A, Berghe H van den: Peripheral primitive neuroectodermal tumour of the cervix. Virchows Arch 2000, 436:68-73.

[9]. Ng SB, Sirrampalam K, Chuah KL: Primitive neruoectodermal tumours of the uterus: a case report with cytological correlation and review of literature. Pathology 2002, 34:455-61.

[10]. McCluggage WG, Sumathi VP, Nucci MR, Hirsch M, Dal Cin P, Wells M, Flanagan AM, Fisher C: Ewing family of tumours involving the vulva and vagina: report of a series of four cases. J Clin Pathol 2007, 60:674-80.

[11]. Sethi B, Smith GT: Primitive neruoectodermal tumours arising in the small bowel. Histopathology 2007, 50:665-6.

[12]. Alvarez-Laso C, Azcano E, Gonzalez J, Gonzalez-Pinto I: Primitive neuroectodermal tumour of the retroperitoneum. Clin Transl Oncol 2008, 10:380-2.

[13]. Su JR, Yang S, Lo KY. Primitive neuroectodermal tumor (PNET) of the kidney. J Urol Roc. 2001;12(4):180-2.

[14]. Gonlusen G, Ergin M, Paydas S, Bolat FA. Primitive neuroectodermal tumor of the kidney: a rare entity. Int Urol Nephrol. 2001;33(3):449-51.

[15]. Banerjee SS, Agbamu DA, Eyden BP, Harris M: Clinicopathological characteristics of peripheral primitive neuroectodermal tumour of skin and subcutaneous tissue. Histopathology 1997, 31:355-66.

[16]. Czekalla R, Fuchs M, Stölzle A, et al: Peripheral primitive neuroectodermal tumor of the stomach in a 14-year-old boy: a case report. Eur J Gastroenterol Hepatol; 16: 1391-1400, 2004.

[17]. Soulard R, Claude V, Camparo P, Dufau JP, Saint-Blancard P and Gros P: Primitive neuroectodermal tumor of the stomach. Arch Pathol Lab Med 129: 107-110, 2005.

[18]. Rafailidis S, Ballas K, Psarras K, Pavlidis T, Symeonidis N, Marakis G and Sakadamis A: Primary Ewing sarcoma of the stomach a newly described entity. Eur Surg Res 42: 17-20, 2009.

[19]. Colovic RB, Grubor NM, Micev MT, Matic SV, Atkinson HD 5. and Latincic SM: Perigastric extraskeletal Ewing's sarcoma: a case report. World J Gastroenterol 15: 245-247, 2009.

[20]. Makoto Inque, Toshifumi Waka, Pavel V. Korita et al. Gastric Ewing sarcoma/primitive neuroectodermal tumor: A case report. Oncology Letters 2: 207-210, 2011

[21]. Zogopoulos G, Teskey L, Sung L, et al. Ewing sarcoma: favourable results with combined modality therapy and conservative use of radiotherapy. Pediatr Blood Cancer 2004;43:35-9. 